provided with slide-valves and appropriate mechanism, which unites the three pairs of chambers into one system, so that the action is continuous and successive.

The external form of Mr. Defries' apparatus is that of a hexagonal prism placed on end; a horizontal diaphragm divides the hexagon into two principal parts, the lower and larger of which is subdivided into three rhomboidal compartments, meeting in the centre; each of these is bisected by a square, perpendicular, and flexible partition, formed of four triangular metal plates, hinged together at their edges by a skin of calf leather, properly prepared, somewhat as in the sides of organ-bellows. Attached to the centre of each flexitle partition is a parallel motion, connected with a perpendicular shaft, which passes through a proper stuffing-box into the superior chamber, where the shaft terminates in an arm which communicates with a central crank; and as there are three such attachments, the expansion and contraction of the moving partitions communicate a rotary motion to the crank, without the necessity of a fly-wheel. Connected with the crank are three rods, moving the three pairs of slide-valves placed on an annular chamber, into which the gas first enters; the slidevalves lead it into those compartments which are expanding, and out of those which are contracting, into the general reservoir.

The pressure of gas on one side of the partition causes the contents of its fellow compartment to be discharged into the common chamber above, from which the measured gas passes direct to the burner. Below the crank of the central spindle, and upon the central axis, is fixed an endless screw, working in a vertical cog-wheel, communicating by ahorizontal spindle with the index-train of wheels, by which the number of cubic feet of gas consumed in a given time is registered on a dial fixed outside the meter.

Trans. Soc. Arts, \&c.

On a Screw-Joint for Water.Pipes, \&c. By Mr. A. M. Perkins.

The mode employed for joining wrought-iron gas-pipes is to cut a right hand screw upon each extremity of every pipe, and to have corresponding sockets screwed at both ends with right hand threads, so that a socket having been screwed on the first pipe, the overhanging part of the socket serves for the reception of the second pipe, and so on. But the pipes do not come into contact.

Mr. Perkins, in his apparatus for warming buildings by a circulation of warm water, employs a right hand screw on the one end, and a left hand screw on the other end, of every pipe, and uses sockets which are tapped with a right and left hand thread at their opposite extremities.

Those ends of the pipe which are cut right hand are left square, whereas, those ends cut left hand are each formed as the frustrum of a cone, in other words, they have sharp, or $\mathrm{V}$ formed, edges. Therefore, when the differently formed extremities of two neighboring pipes are held at rest by means of gas tongs, and the socket alone is turned round, the pipes simultaneously enter the socket, and ultimately forci- 
bly meet, so that the sharp edge of the one pipe is indented into the flat surface of the adjoining. The joints thus produced have been found capable of sustaining every pressure to which they have been applied, and the pipes themselves endure, without bursting, an expansive force of 3000 lbs. on the square inch.

The same principle is applied to cast-iron pipes for water-mains, \&c., the right and left hand screws being cast on each pipe, and the sockets are also cast in iron. In these cases a mill-board annular washer, soaked in oil, is placed between the flat ends of the two pipes, which are screwed together by the double nut, as in the former case.

Ibid.

\section{A New Gas.}

The "Censeur," of Lyons, states, that at one of the late sittings of the municipal council, a trial was made of a new portable gas, to which its inventor has given the name of "hydroluminous." The apparatus, says this journal, is very simple, and applicable to the smallest candlesticks, as well as to the largest and most splendid candelabra. The light it gives is very fine, and it is so portable that it can be carried about with the common hand candlestick.

Lond. Mech. Mag.

\section{Silver Plating as practiced at Sheffield. By Mr. Роттев, Jr.}

Plating on copper was first introduced in the year 1742, by Mr. Thomas Bolsover, a member of the Corporation of Cutlers, at Sheffeld, who, when repairing a knife-handle, composed partly of silver, and partly of copper, suddenly thought that it might be possible so to unite the two metals as to form a cheap substance, which, presenting an exterior of silver, might be used for the manufacture of several articles hitherto made entirely of that metal. It was not till about forty years after the introduction of Mr. Bolsover's plan, that the ornamentêd parts of plated articles, called mountings, were constructed of silver. This great improvement caused the manufacture of plated wares to become one of the staple trades of Sheffield.

There are two important features in the process of silver plating, the one a perfect adhesion of the two metals, the other a protection from wear of the prominent edges by friction.

The process of manufacturing plated articles may be described as follows:-

An ingot of copper being cast, and the surfaces carefully prepared by filing, so as to remove all blemishes, and a piece of silver, also having one surface perfectly cleaned, are tied together by means of iron wire. A paste of borax and water is then passed round the edges with a quill, and the mass being placed in a common air furnace, is heated to a proper temperature, which is ascertained by means of a small aperture in the door. As soon as the union of the two bodies is effected, which is known by the oozing of the metal when the fusion of the two metals has taken place, the bar is removed from 